\title{
Local and global factors of similarity in visual search
}

\author{
MICHAEL VON GRÜNAU and STÉPHANE DUBÉ \\ Condordia University, Montreal, Quebec, Canada \\ and \\ CÉSAR GALERA \\ University of Sao Paulo, Ribeirao Preto, Brazil
}

\begin{abstract}
Effects of the similarity between target and distractors in a visual search task were investigated in several experiments. Both familiar (numerals and letters) and unfamiliar (connected figures in a $5 \times 5$ matrix) stimuli were used. The observer had to report on the presence or absence of a target among a variable number of homogeneous distractors as fast and as accurately as possible. It was found that physical difference had the same clear effect on processing time for familiar and for unfamiliar stimuli: processing time decreased monotonically with increasing physical difference. Distractors unrelated to the target and those related to the target by a simple transformation $\left(180^{\circ}\right.$ rotation, horizontal or vertical reflection) were also compared, while the physical difference was kept constant. For familiar stimuli, transformational relatedness increased processing time in comparison with that for unrelated stimulus pairs. It was further shown in a scaling experiment that this effect could be accounted for by the amount of perceived similarity of the target-distractor pairs. For unfamiliar stimuli, transformational relatedness did have a smaller and less pronounced effect. Various comparable unrelated distractors resulted in a full range of processing times. Results from a similarity scaling experiment correlated well with the outcome of the experiments with unfamiliar stimuli. These results are interpreted in terms of an underlying continuum of perceived similarity as the basis of the speed of visual search, rather than a dichotomy of parallel versus serial processing.
\end{abstract}

Visual search tasks have been used extensively to study the processes of early vision by which the visual system comes to make a quick analysis of the visual scene. The purpose of such an analysis is to extract some more or less rudimentary structure from the impinging visual array in order that later processes can apply more stringent and more accurate analyses. A quick but distributed analysis (perhaps over the whole visual field) can guide slower and more focused analyses (Hoffman, 1979; Wolfe, Cave, \& Franzel, 1989). The latter processes would require that attention be paid to particular regions and stimulus aspects, while the early process needs few attentional facilities (Julesz, 1984, 1986; Treisman, 1986; Treisman \& Gormican, 1988).

In many visual search tasks, the absence or presence of a target stimulus among a variable number of distractor stimuli has to be determined on each trial. Obviously, this can be accomplished only if the distractors are in some way different from the target. And the greater this dif-

This research was supported by Canadian NSERC Operating Grant A-53 to M.v.G. Travel assistance was received by M.v.G. from CCintUSP (Brazil). Correspondence should be addressed to $M$. von Grünau. Department of Psychology, Concordia University, 1455 de Maissonneuve Blvd. W., Montreal, Quebec, Canada H3G 1 M8.

-Accepted by previous editor, Charles W. Eriksen ference, the easier presumably is the search task. Several stimulus attributes, such as color, motion, or orientation, have been investigated in this respect (see, e.g., Beck, 1982; Nothdurft, 1985, 1990, 1991). Many approaches have been used to examine aspects of shape difference, leading to the formulation of various underlying processes. Duncan and Humphreys (1989) suggested that both target-distractor dissimilarity and interdistractor similarity will increase the efficiency with which distractors can be rejected.

The efficiency with which attention is directed to relevant regions of the display varies as a function of the relationship between the target and the distractors. The localization of the target is difficult when the target and the distractors belong to the same category (Estes, 1972), or when the target and distractors become increasingly similar to each other (Farmer \& Taylor, 1980; Pashler, 1987). In general, the similarity relationship between the stimuli has been defined by the transformations that would be necessary to transform one into the others, or likewise by the number of characteristics that they have in common. According to the former idea, which is related to the idea of a gestalt, our perceptual system would be sensitive to relationships within and between shapes, and the detectability of a target would depend on its global similarity to other shapes (Singer \& Lappin, 1976). According to the latter idea, the similarity between two objects 
would be determined by the number of features shared by them when their shapes are superimposed (McIntyre, Fox, \& Neale, 1970).

The number of dimensions shared by target and distractors has been used as one estimate for similarity in visual search studies in which the stimuli are defined by a conjunction of attributes (Dehaene, 1989; Quinlan \& Humphreys, 1987). The results of these studies have suggested, first, that the subjects are able to restrict the search to only a portion of the stimuli which share some relevant feature with the target, and second, that the search, even though much faster, remains serial and is based on discrete features. Some of these studies have yielded little evidence for preattentive processing of emergent features (Treisman, 1988; Treisman \& Paterson, 1984). Other studies have not only yielded results incompatible with parallel detection of certain conjunctions, but also suggested that the addition of features is independent and additive with respect to search time (Treisman \& Sato, 1990).

On the other hand, some studies suggest the importance of gestalt factors in determining the efficiency with which a target can be detected in the presence of distractors. In line with this contention, targets that establish a relationship of good form or good continuation with the distractors are detected more slowly than targets that do not have such a relationship (Prinzmetal \& Banks, 1977). Similarly, other results suggest that context allows the formation of emergent features that behave like functional units in perception and that can be detected in parallel (Pomerantz, Sager, \& Stoever, 1977).

A comparison between the two conceptions of similarity was carried out by Singer and Lappin (1976). These authors evaluated the effect on search time of geometric transformations that conserved the number of points (deletions and breaks) and of transformations that changed the number of points but preserved the general appearance of the shape (left-right mirror image) of the stimuli. The idea was that evidence against the conception of similarity based on the number of common features could be obtained if the reverse transformation appeared to be detected with more difficulty, despite the difference between the points. The results, however, showed that, when a reverse transformation introduced differences in inclination between the target and the distractors, its detection was fast and independent of the number of distractors. This was in contrast to results with transformations that kept the number of common points between the two shapes constant.

In our experiments, we examined the effects on visual search when target and distractors differed on the most primitive aspect of form, simple template coincidence, which we called physical difference, or, keeping this difference constant, when they differed on other, more global factors of shape similarity. We used both familiar and nonfamiliar stimulus sets. We found that in addition to and independently of physical difference, certain more global relationships between the items (transformations like rotation and reflection) determined the search times. We also found that this result could be predicted from the directly perceived target-distractor similarity.

\section{EXPERIMENT 1}

In assessing the difference between two stimuli, a first approach might be to attempt to measure how many elements (constituent parts) differ between the two. This we call the physical difference, because it implies no further assumptions about special relations between elements. In this experiment, the influence of the physical difference between target and distractor on the ease of visual search was examined for a set of familiar stimuli.

\section{Method}

Subjects. The observers consisted of 2 of the authors (M.v.G., S.D.) and 4 naive subjects recruited among psychology students, all with normal $(20 / 20)$ or corrected-to-normal vision.

Stimuli. For stimuli, we used the digits 0-9; where 9 was always the target, and the others served as distractors (see Figure 1). The stimuli consisted of the appropriate number of horizontal and vertical rectangular bars and were $2.4^{\circ}$ high and $1.3^{\circ}$ wide. The physical difference between them was defined operationally but arbitrarily as the number of these bars that had to be removed or added to transform one into the other. This definition was originally used by Van Nes and Bouma (1980). Thus 3, 5, and 8 had a difference of 1 with respect to $9 ; 6,0$, and 4 , a difference of $2 ; 7$ and 2 , a difference of 3 ; and 1 , a difference of 4 . The stimuli were presented as black $\left(1.78 \mathrm{~cd} / \mathrm{m}^{2}\right)$ on a white background $\left(71.9 \mathrm{~cd} / \mathrm{m}^{2}\right)$ on the color monitor of a Macintosh II computer. They were distributed in a matrix of 3 rows and 4 columns subtending an overall area of $20^{\circ} \times 15^{\circ}$ of visual angle at the observation distance of $57 \mathrm{~cm}$. The stimuli were jittered horizontally and vertically within their matrix cells to induce random misalignments.

Procedure. The VSearch software (Enns, Ochs, \& Rensink, 1990) was used to control the experiment. Each combination of the target

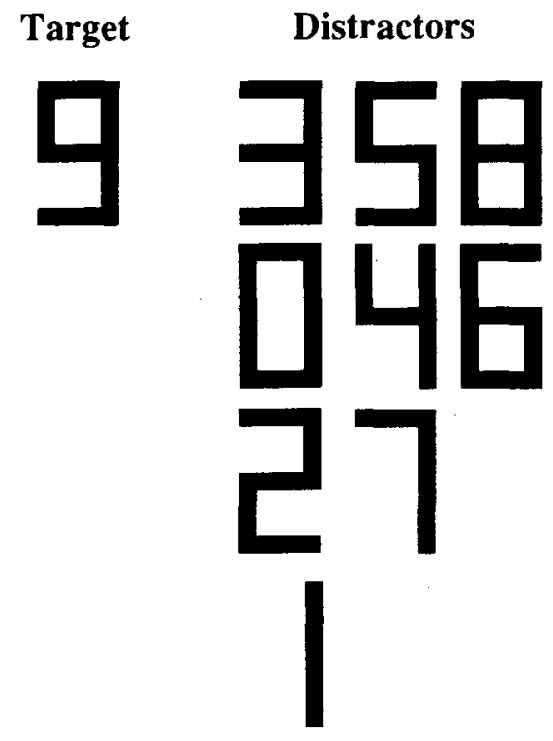

Phys. Diff.

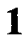

2

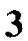

Figure 1. Target and distractor stimuli used in Experiment 1, grouped by physical difference. Actual size was $2.4^{\circ} \times 1.3^{\circ}$ of visual angle. 
and one of the distractors constituted a condition (a total of nine), and conditions were presented to each observer in a randomized order. Before the beginning of each condition, the observer was shown and familiarized with the target and distractor. In each condition, trials were presented in three blocks of 60 trials each, a total of 180 trials. On half the trials the target was present, on the other half not, and there were three display sizes $(1,6$, and 12 items). The $6(2 \times 3)$ combinations of these two variables were presented 30 times each to give the total of 180 trials for each of the nine conditions. The order of presentation was randomized by the program.

The observer's eye was positioned by a chin- and forehead rest at a distance of $57 \mathrm{~cm}$ from the screen, and he/she had to press keys to indicate as fast and as accurately as possible whether the target was present or absent. The stimuli remained on the screen until a response was given or up to a maximum of $2 \mathrm{sec}$. Reaction time (RT) and errors were recorded. After each trial, a small " + ", or " - " at the center of the screen informed the observer of the correctness of the response. These also served as the fixation point for the next trial. After each block, which was initiated by the observer when ready, the error rate was given, and the observer was urged to keep errors below $10 \%$.

\section{Results and Discussion}

For each condition, mean RT and error rates were calculated for each observer for target present/absent and
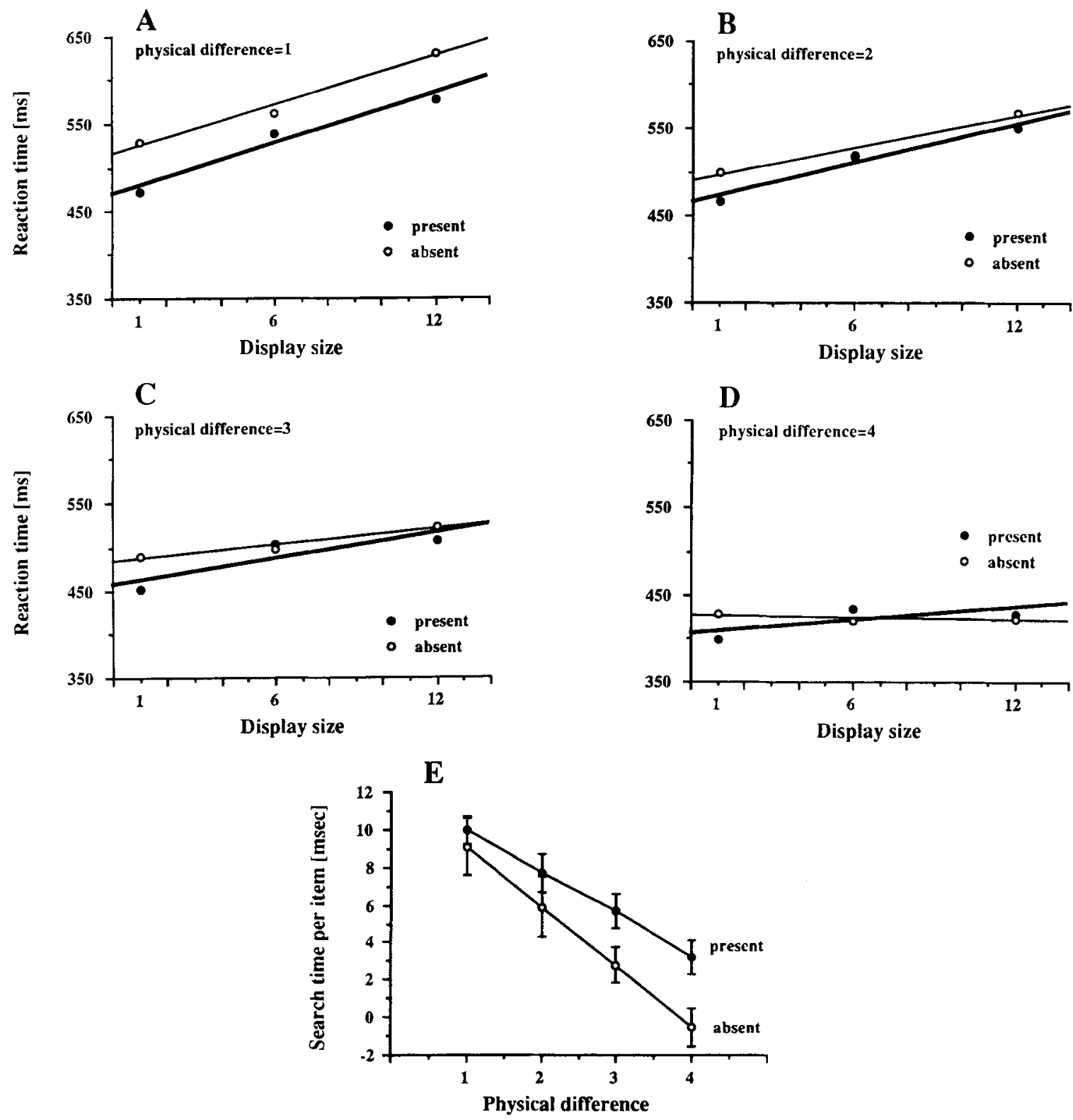

Figure 2. (A-D) Reaction times (in milliseconds) as a function of display size, averaged over the 6 observers in Experiment 1 , for the stimuli in Figure 1. Each panel represents a specific level of physical difference, averaged over the various digits at that level. Both target present and target absent trials are graphed with their linear regression functions. (E) Mean processing times (slopes of the linear regression functions) obtained from the RT-display size relationships in Experiment 1 for target present and absent as a function of physical difference, with standard errors, for the stimuli of Figure 1. 
Table 1

Mean Processing Times (Slopes) for All Distractor Stimuli Used in Experiment 1

\begin{tabular}{ccr}
\hline & \multicolumn{2}{c}{ Target } \\
\cline { 2 - 3 } Distractor & Present & Absent \\
\hline \multicolumn{4}{c}{ Physical difference $=1$} \\
8 & $9.5 \pm 1.6$ & $5.8 \pm 2.4$ \\
5 & $9.8 \pm 1.3$ & $12.7 \pm 1.9$ \\
& $10.7 \pm 2.2$ & $8.7 \pm 1.3$ \\
6 & Physical difference $=2$ & \\
4 & $13.3 \pm 1.9$ & $14.8 \pm 4.0^{*}$ \\
0 & $4.3 \pm 1.4$ & $0.8 \pm 1.4$ \\
& $5.5 \pm 0.8$ & $2.0 \pm 0.9$ \\
2 & Physical difference $=3$ & \\
7 & $7.3 \pm 0.8$ & $5.7 \pm 1.7$ \\
& $4.0 \pm 1.1$ & $0.0 \pm 0.8$ \\
1 & Physical difference $=4$ & \\
& $3.2 \pm 0.9$ & $-0.5 \pm 0.9$ \\
\hline
\end{tabular}

*Indicates the special case of the distractor 6 (see Experiment 3 ).

the three display sizes. Error rates remained consistently under $10 \%$, and there was no speed-accuracy tradeoff. (The error rates for this and all other experiments are reported in Table 4.) The RT data are summarized in Figures 2A-2D. Mean RT is graphed as a function of display size for the four categories of physical difference, averaging over all instances within each category. There was a significant decrease of mean RT as physical difference increased $[F(3,15)=24.2, p<.0001]$, indicating that the task became easier. The highly significant interaction between physical difference and display size $[F(6,30)$ $=13.9, p<.0001]$ shows that the increase in RT with display size became slower as physical difference increased. From the RT data, the slope of the linear relationship between RT and display size was calculated by linear regression. These slopes represent the mean processing time per item. Table 1 gives these slopes as means for all observers with $\pm 1 S E$ for target present and target absent for all nine conditions, grouped according to the physical difference between target and distractor. All slopes were fairly small, which might be the result of the relatively large stimuli (Duncan \& Humphreys, 1989). The task, therefore, might have been relatively simple, regardless of physical difference. Nonetheless, there were reliable differences between the slopes in the different conditions $[F(3,15)=27.4, p<.0001]$.

In Figure 2E, these slopes for target present and target absent are graphed as a function of physical difference. The data for the conditions that belong to the same category of physical difference were averaged. Clearly, both curves indicate that processing time decreased as physical difference increased. Curiously, the target present trials had consistently a slightly steeper slope than the target absent trials had. From the RT graphs, it appears that this might have been due to the particularly slow responses in the case when only the target was present. Overall, however, it is clear that the greater the physical differ- ence between target and distractor digits, the easier it was to find the target.

Although this experiment showed that physical similarity increased processing time, the facts that all slopes were fairly flat ( $\leq 10 \mathrm{msec}$ ) and that there was only a small difference between the target present and absent conditions $[F(1,5)=7.3, p<.05]$ suggest that processing might have occurred almost in parallel and was certainly very fast. In the next experiment, physical difference was again assessed with significantly smaller stimuli.

\section{EXPERIMENT 2}

Even though there were reliable differences in processing speed as a function of physical difference in Experiment 1 , it has become customary in such tasks to look for evidence for both parallel and serial processing. The processing times (slopes) obtained in Experiment 1 were generally too small for such an analysis. We therefore repeated the experiment under more difficult conditionswith smaller stimuli.

\section{Method}

Subjects. Data were collected from 4 observers, including one of the authors (C.G.) and 3 naive psychology students.

Stimuli. Digits similar to those in Experiment 1 were used here, but their overall size was only $1.2^{\circ} \times 0.7^{\circ}$. The digit 5 was chosen as the target. The distractors were 6 and 9 , with a physical difference of 1 ; and 0 and 4 , with a difference of 3 . The stimuli were drawn on white cardboard $\left(8^{\circ} \times 8^{\circ}\right)$, and for each display size 40 cards ( 10 for each distractor) were made, on which the stimuli were distributed randomly among the 35 possible locations (5 rows $x$ 7 columns). The target replaced a distractor on $50 \%$ of the trials. These cards were presented by a Lafayette Model 40010 tachistoscope with a GE 415-CW lamp to which a timer and an alarm were connected.

Procedure. The observers had to press buttons to indicate whether the target was present or not, and their RTs were recorded. The target was present on $50 \%$ of the trials. Each observer participated in two sessions, each of which consisted of two blocks of 60 trials, of which the first 12 each were for practice. In one session, the blocks were mixed; that is, trials with distractors of both Ievels of physical difference were presented in a randomly intermingled fashion (mixed blocks). In the other session, each block had only trials of one of the two levels of physical difference (pure blocks). The order of presentation of sessions and blocks was counterbalanced across subjects. The two possibilities for each level of physical difference were always presented in the same block but randomly interspersed. Three levels of display size were used: 2,8 , and 16 items. Their order and that of target present/absent were randomized individually. The alarm was sounded $700 \mathrm{msec}$ before each stimulus presentation. No fixation point was used, but the observers were instructed to look at the center of the display and used a chinrest at a viewing distance of $30 \mathrm{~cm}$.

\section{Results and Discussion}

Error rates remained below $10 \%$ for all conditions and showed no speed-accuracy tradeoffs (see Table 4). In the analysis of RT, results for the two distractors within a given level of physical difference were combined, since there were no significant differences. Since the results for 
A

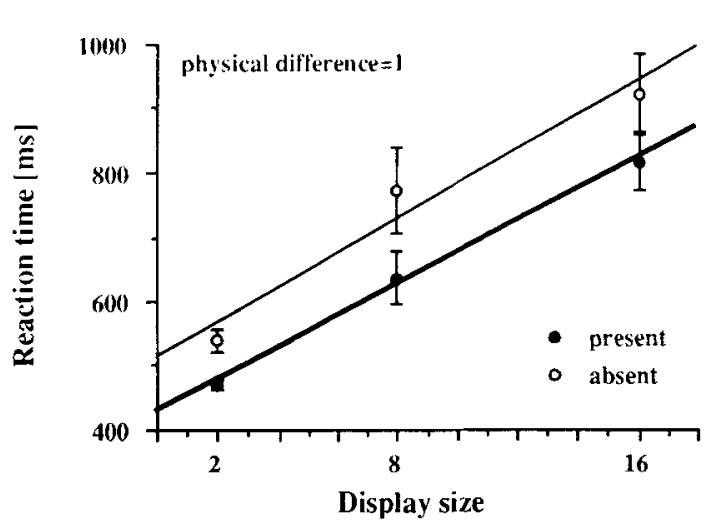

B

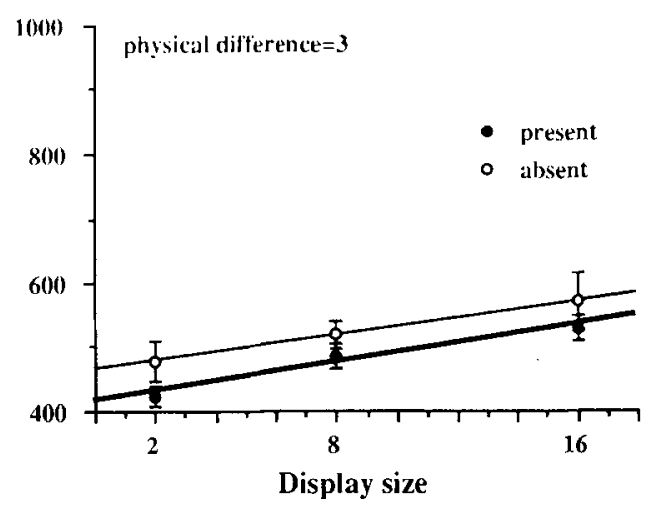

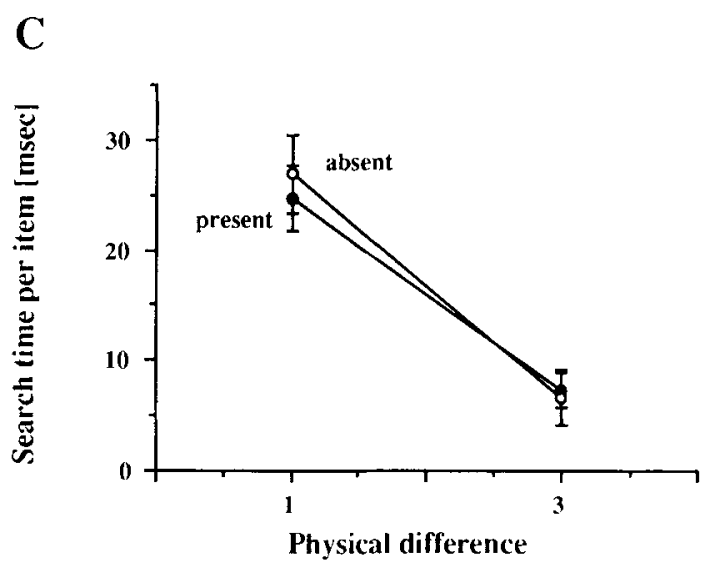

Figure 3. (A and B) Reaction time as a function of display size for Experiment 2 for the two levels of physical difference, averaged over 4 observers. Target present and absent trials with their linear regression functions are graphed. (C) Mean processing times (slopes) obtained in Experiment 2 for target present and absent as a function of physical difference, with standard errors. Stimulus size: $1.2^{\circ} \times 0.7^{\circ}$ of visual angle.

the mixed and pure blocks did not differ significantly either, they were also combined. In Figures 3A and 3B, $\mathrm{RT}$ is graphed as a function of display size for the two levels of physical difference. Again, mean RT decreased significantly with increasing physical difference $[F(1,3)=$ $135.5, p<.0015]$. The significant interaction between physical difference and display size $[F(2,6)=17.3, p<$ $.0033]$ also indicated that processing was more difficult for the smaller physical difference. From the RT versus display size relationships the slopes were calculated by linear regression. These are graphed in Figure $3 \mathrm{C}$ for target present and absent as a function of physical difference.

The influence of physical difference on the slopes was even stronger here than in Experiment $1[F(1,3)=33.8$, $p=.01]$. The smaller size of the stimuli and/or the different form of presentation yielded steeper slopes (and longer RTs). A physical difference of 1 now presented a difficult task with a long mean processing time per item ( $>25 \mathrm{msec}$ ); the task with a physical difference of 3 was comparatively easy $(<10 \mathrm{msec})$. The slopes for the difference of 1 could be considered as typical for serial pro- cessing; those for a difference of 3 could be considered as typical for parallel processing. The finding that the slopes for the target present and absent conditions did not differ significantly $[F(1,3)=0.066, p=.81]$, however, speaks against this simple classification (Humphreys, Quinlan, \& Riddoch, 1989).

These two experiments establish clearly the strong effect that physical difference between target and distractor has on the speed of a visual search task. The fact that this effect held up under different conditions of presentation and for different stimulus sizes shows the robustness of this variable. From a detailed examination of Table 1 , however, it appears that especially distractor 6 did not behave just according to its physical difference from the target 9 . We note that 6 is a simple rotation of 9 , and this relationship might have introduced a special similarity (other than that based on the difference in building blocks) to make the task more difficult. This possibility was examined in more detail in the next two experiments. Similarly, 2 seems to have been a more effective distractor than 7 , both of them having a physical difference of 3 . 
(See the General Discussion for the possible influence of more global factors in this case.)

\section{EXPERIMENT 3}

When target and distractor differ in physical structure, they will usually be two unrelated items (like, e.g., a 9 and a 4). At other times, they may also be related by some kind of transformation, as a 9 is related to a 6 by a rotation. Irrespective of physical difference, being related by a transformation may increase the similarity between target and distractor. In Experiment 3, we examined the effect of some transformations, keeping physical difference constant.

\section{Method}

Subjects. Two of the authors (M.v.G., S.D.) and 4 naive undergraduate students, all with normal or corrected-to-normal vision, served as the subjects.

Stimuli. The stimuli were digits and one letter and their transformations. All stimuli and conditions for the experiment are displayed in Figure 4. Their physical dimensions were $1.2^{\circ} \times 0.7^{\circ}$. As before, they were presented on the color monitor of a Macintosh II computer that also controlled the stimulus presentation and data collection.

In all target-distractor combinations, the physical difference was kept constant at a value of 2 . Four different types of relationships were applied: three conditions in which the target and the distractor were unrelated; two conditions in which the distractor was a rotation of $180^{\circ}$ of the target; and two conditions in each of which the distractor was either a horizontal or a vertical reflection (reflection on a horizontal or vertical axis) of the target.

Procedure. The procedures were the same as described for Experiment 1 . The nine conditions were presented to each observer in a different random order. Usually, two sessions were required for an observer to complete all conditions. The display sizes were 2,8 , and 16 items. RTs and errors were measured as before.

\section{Results and Discussion}

Error rates were generally below $10 \%$, and no speedaccuracy tradeoffs occurred (see Table 4). For illustrative purposes, RT is graphed in Figures 5A-5D as a function of display size for one of the unrelated pairs $(9,4)$ and for the target 4 with its rotated $(4,4$ rot $)$, horizontally $(4,4 \mathrm{hr})$ and vertically $(4,4 \mathrm{vr})$ reflected distractors. Mean RT was clearly fastest for the unrelated pair and slowest for the pair with vertical reflection. RTs for the other conditions followed the same pattern, as was true when corresponding conditions were combined into groups according to the relationship between target and distractors. An analysis of these four groups of relationship showed significant differences $[F(3,15)=25.5, p<.0001]$, verifying that relatedness by transformation did influence the speed of visual search and might thus contribute to the perceived similarity of target and distractor in such a search task (see next experiment). This is also supported by the highly significant interaction between relatedness condition and display size $[F(6,30)=8.6, p<.0001]$. As before, the slopes (mean search times per item) were calculated from the RT-display size relationship for target present and target absent in all nine conditions by linear regression. These are plotted in Figure 5E, grouped by the kind of relationship. In the inset, means are given for the four conditions of relatedness.

Though there were differences between certain conditions within the same relationship, it is clear that processing was easiest (smallest slopes and RTs) for unrelated items, followed by rotation, horizontal reflection, and vertical reflection, which was most difficult (steepest slopes and longest RTs). Statistical analysis, comparing the four groups of relatedness in terms of slopes (see inset in Figure 5), shows a strong effect $[F(3,15)=9.3, p<.001]$. Only for the unrelated items was there the possibility of parallel processing, based on short search times. For all other relationships, search times were longer and target absent was almost twice as long as target present $[F(1,5)=$ $15.8, p=.01$ ], suggesting a serial self-terminating process. Post hoc tests (Duncan, Neuman-Keuls, and $t$ test, with $p<.05$ ) indicated that the unrelated group of pairs had smaller slopes than did any of the transformations, and that vertical reflection had larger slopes than did all the other conditions.

Our results, therefore, demonstrate that more global relationships between target and distractor significantly determine the ease with which they can be differentiated in a search task, even when physical difference is kept constant. Our data suggest that all global relationships tested here had the effect of increasing the similarity between target and distractor, yet not to the same degree. Furthermore, examination of the individual conditions suggests that being related by a particular transformation does not per se determine the ease of visual search. Thus, with reference to Figure 5, a 4 reflected on the vertical axis (4vr) appears to be more similar to the 4 than a 4 reflected on the horizontal axis (4hr). Similarly, a vertically reflected $9(9 \mathrm{vr})$ and a horizontally reflected $9(9 \mathrm{hr})$ seem to be equally similar to a 9. Comparison of rotation and horizontal reflection shows that a rotated 4 (4rot) and a horizontally reflected $4(4 \mathrm{hr})$ seem to be equally similar, while a rotated 9 (9rot) seems to be less similar to a 9 than a horizontally reflected $9(9 \mathrm{hr})$. In Experiment 4 , we tested this similarity hypothesis with a different approach.

\section{EXPERIMENT 4}

We have seen that in some cases physical difference between target and distractor can be a good predictor for processing time in visual search tasks (Experiments 1 and 2 ), whereas in other situations big differences in processing time are obtained, even though physical difference remains constant. In that case, processing time may be considered as an estimate for the similarity between target and distractor (Podgorny \& Garner, 1979). In order to avoid the circularity of argument that is easily found in this respect (i.e., similarity between target and distrac- 


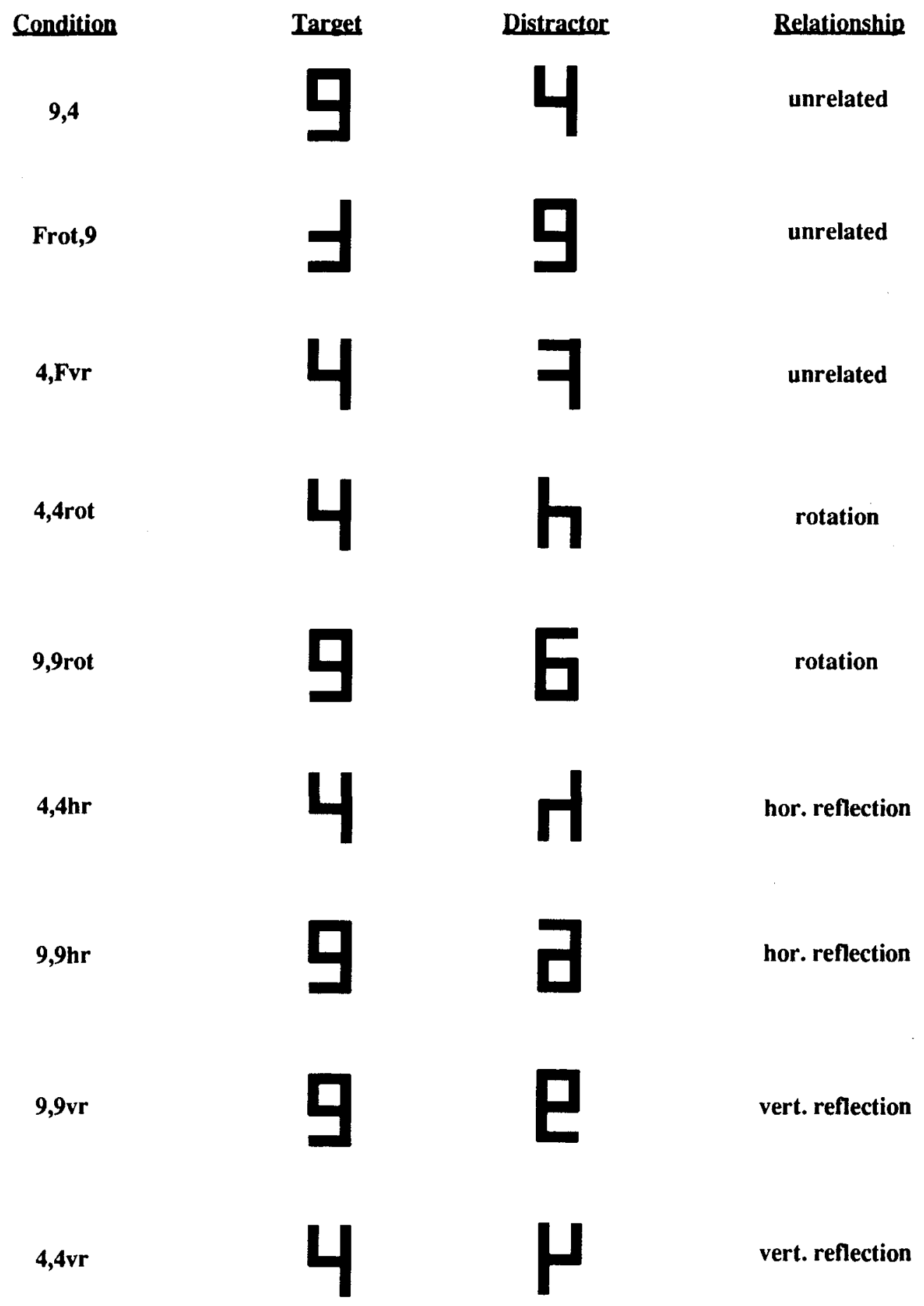

Figure 4. Stimulus pairs for Experiments 3 and 4, listed in terms of the relationship between target and distractor. 
A

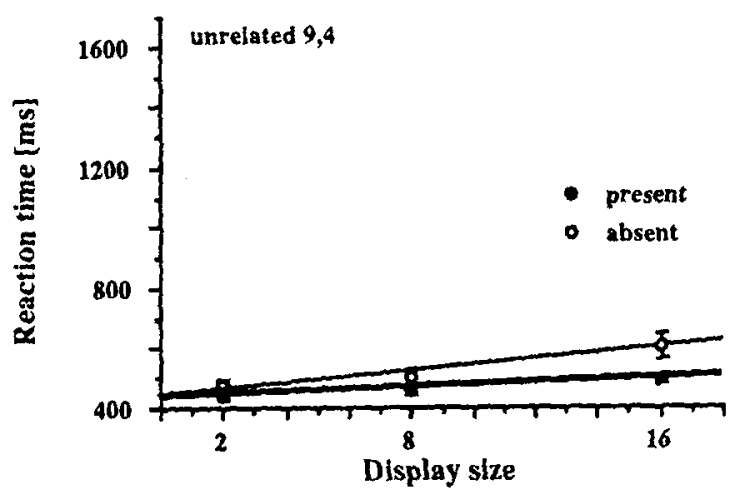

C

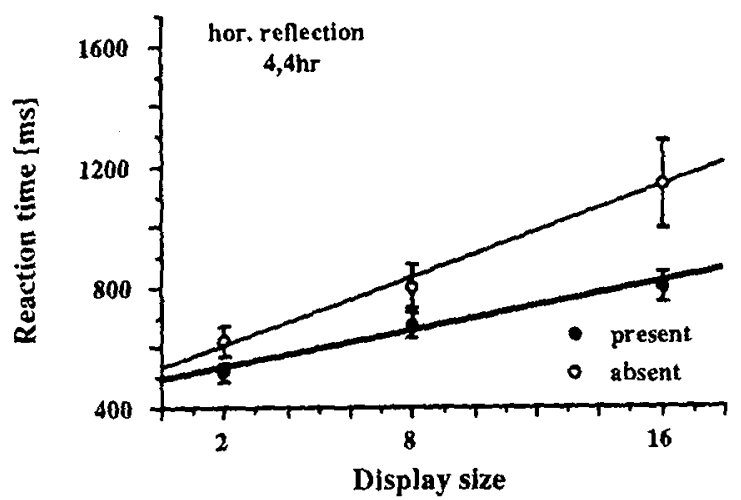

B

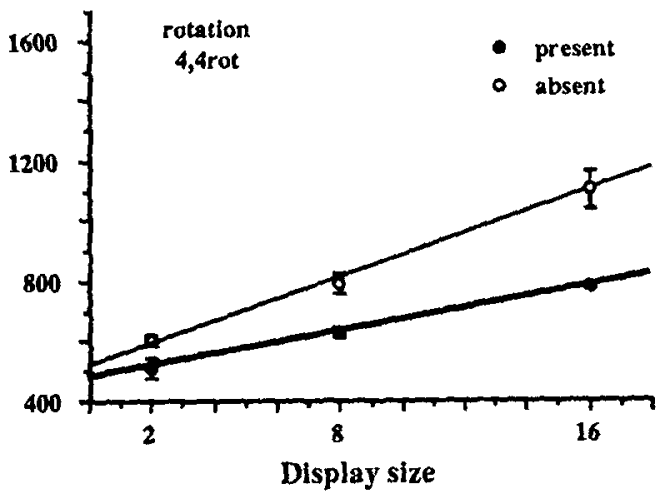

D

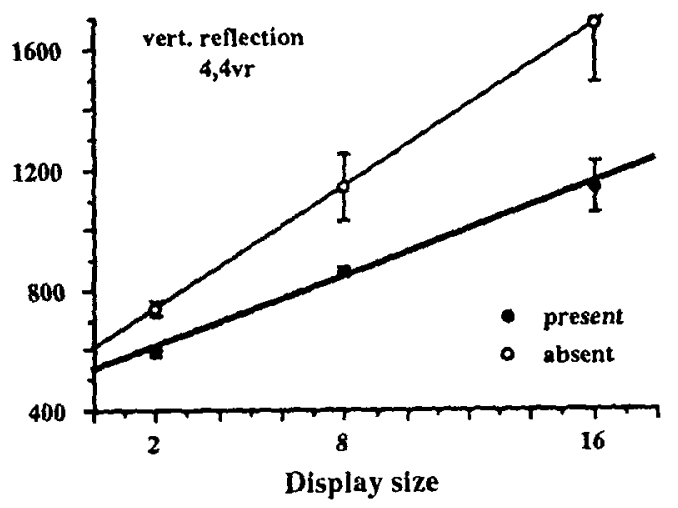

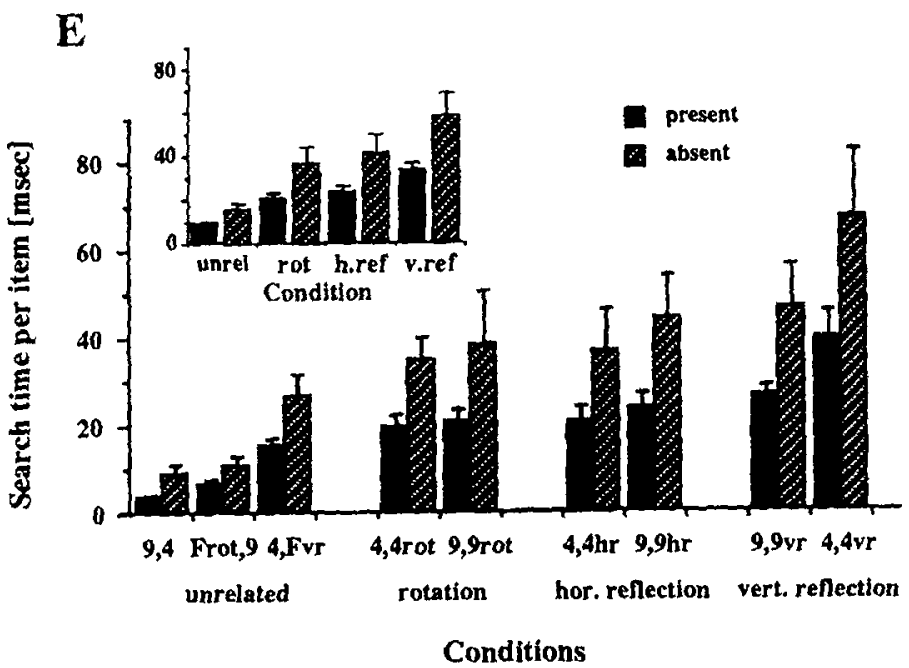

Figure 5. (A-D) Reaction times as a function of display size for some of the target-distractor pairs of Experiment 3, averaged over the 6 observers, with standard errors. Target present and absent trials are graphed with linear regression functions. (E) Mean processing times (slopes) for all stimulus pairs in Experiment 3 with the parameter of target presence, arranged according to the relationship between target and distractor, with standard errors. The inset shows the same in terms of means for the four kinds of relationships between target and distractor (unrelated, rotation, horizontal and vertical reflection). 
tors leads to longer search times; therefore, if we find longer search times, this indicates greater similarity), it is necessary to have an independent measure of similarity.

One way to achieve this is to evaluate the structure of similarity in these stimuli according to the methods of scaling. These methods are useful when we do not have a measuring scale for a dimension that we want to evaluate. The scaling method used in this experiment allowed us to derive a measurement for the stimuli according to the judgments given by the observers.

\section{Method}

Subjects. There were 76 subjects ( 69 female, 7 male) from three undergraduate psychology classes at the University of Sao Paulo in Ribeirao Preto, Brazil, in the experiment.

Stimuli. The same pairs of items that were used in Experiment 3 as target-distractor pairs in a search task were also presented here. Each pair was reproduced on a cardboard $(6.5 \times 2.5 \mathrm{~cm})$, with each element being $12 \times 7 \mathrm{~mm}$. In the center between the stimuli, an arrow indicated the correct viewing direction.

Procedure. We used the ranking method. This method demands only that the stimuli be ordered according to a specified dimension-in our case, the perceived similarity between target and distractor. Knowing the distributions of the stimulus pairs in the different categories lets us determine the distances and scale values of each stimulus pair in the psychological continuum (Guilford, 1954) or simply the mean ranking of each stimulus in that dimension (Woodworth, 1938).

Every subject received an envelope that contained the nine cardboards with the stimulus pairs. They were instructed to observe the stimuli and to arrange them in order of decreasing similarity between the two members of a pair. In this way, they defined nine categories in the order of greatest to smallest similarity.

\section{Results and Discussion}

The means obtained with the ranking method (Woodworth, 1938) are presented in column 2 of Table 2 for the nine stimulus pairs. The larger values represent the most dissimilar stimulus pairs. According to this, the pair Frot, 9 should be considered the most dissimilar, followed by the pairs $4, F v r$ and 9,4 . These were the three unrelated stimulus pairs. The stimulus pairs with the transformations rot and hr follow, and the most similar pairs were those with the transformation vr.

Table 2

Mean Rank for All Target-Distractor Pairs Used In Experiment 4

\begin{tabular}{lcc}
\hline Stimulus Pair & Mean Rank \\
\hline \multicolumn{3}{c}{ Unrelated } \\
Frot,9 & & 6.9 \\
$4, \mathrm{Fvr}$ & & 7.9 \\
& Rotation & 7.3 \\
$4,4 \mathrm{rot}$ & & 5.2 \\
$9,9 \mathrm{rot}$ & & 4.0 \\
& & \\
& Horizontal Reflection & 5.6 \\
$4,4 \mathrm{hr}$ & & 3.8 \\
$9,9 \mathrm{hr}$ & & \\
& Vertical Reflection & 2.0 \\
$9,9 \mathrm{vr}$ & & 2.4 \\
$4,4 \mathrm{vr}$ & & \\
\hline
\end{tabular}

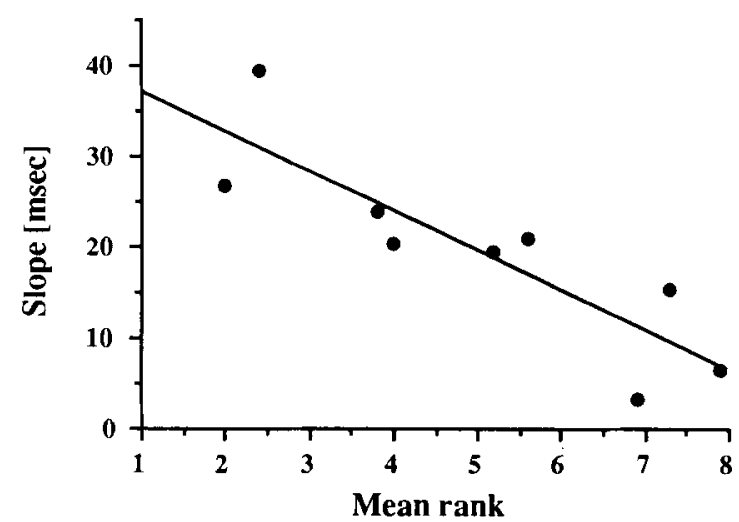

Figure 6. Correlation between the mean processing times for target present trials in a search task (Experiment 3) and the mean rank in a similarity scaling task (Experiment 4) for the same targetdistractor pairs as those in Figure 4.

Every observer's estimates were subjected to a Friedman ANOVA. This analysis allowed us to confirm that the stimulus pairs can be arranged into different levels of similarity in a significant way $\left[\chi^{2}(8)=365, p<\right.$ .00011 . The consecutive pairs were a posteriori compared two by two using a Wilcoxon signed-rank test. The stimuli of the pair 9,4 cannot be considered more similar than the stimuli of the pair $4, \operatorname{Fvr}(p=.11)$. Similarly, the same degree of similarity is given by the pairs 4,4 rot and $4,4 \mathrm{hr}(p=.09)$, the pairs $9,9 \mathrm{rot}$ and $9,9 \mathrm{hr}(p=.65)$, and the pairs $9,9 \mathrm{vr}$ and $4,4 \mathrm{vr}(p=.16)$.

Intuitively, then, one can group the stimulus pairs into three categories. These three categories are also evident from a cluster analysis of the differences between means (using Johnson's, 1967, single-linkage algorithm). One grouping, composed of the most different pairs, contains the nonrelated stimuli (Frot,9, 4,Fvr, and 9,4). A second grouping, made up of the most similar pairs, is defined by the vertical reflection $(4,4 \mathrm{vr}$ and $9,9 \mathrm{vr})$. The third grouping, defined by the transformations of rotation and horizontal reflection $(4,4 \mathrm{rot}, 4,4 \mathrm{hr}, 9,9 \mathrm{rot}$, and 9,9hr), contains the stimulus pairs with intermediate levels of similarity. These three categories are indicated in Table 2 by dashed horizontal lines.

The order of stimulus pairs displayed in Table 2 seems similar to that obtained in Experiment 3 for visual search. We therefore looked at the correlation between the slopes when the target was present and the similarity scale values, using the mean rank values from Table 2 (see Figure 6). The obtained correlation was fairly high $(r=.86, p<$ $.001)$. These results therefore suggest that both physical difference and more global transformations may operate through the perceived similarity between target and distractors.

\section{EXPERIMENT 5}

In all the preceding experiments, the stimuli were very familiar, like digits or letters, or they were simple trans- 
A

Target

a1

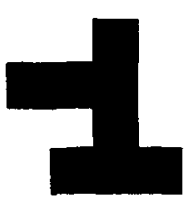

a2

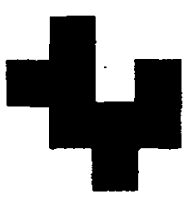

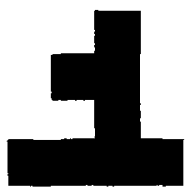
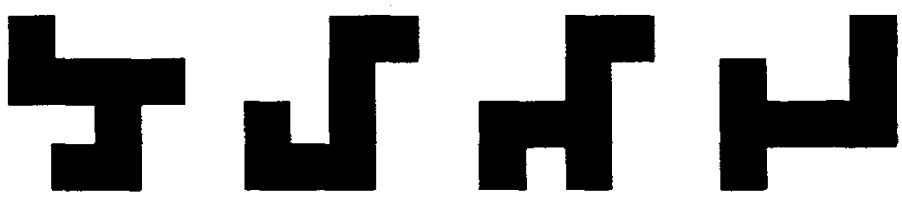

Distractors
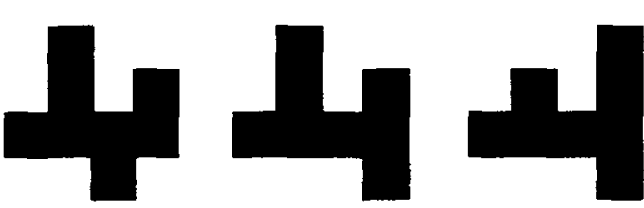

3
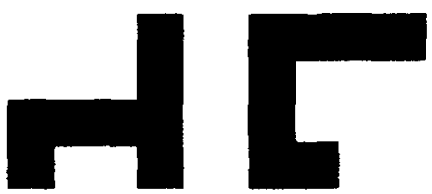

2

4

6

Physical difference

B

\section{Target}

b1

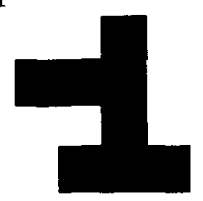

b2

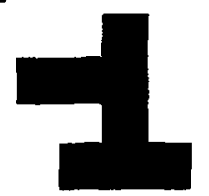

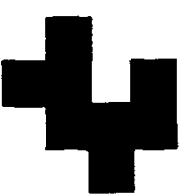

1

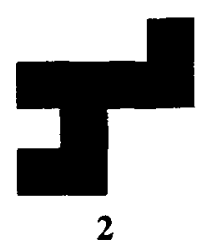

unrelated

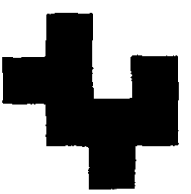

old

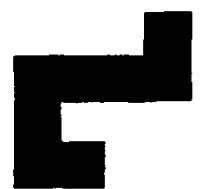

n1
Distractors
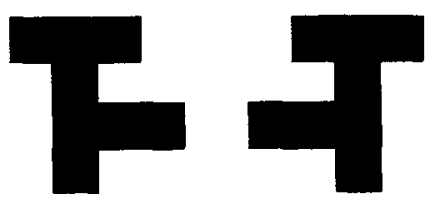

rotation

hor. reflection
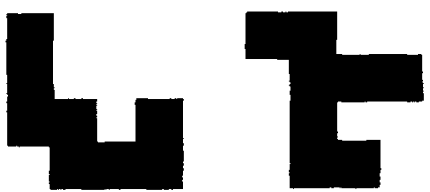

n2

n3 vert. reflection
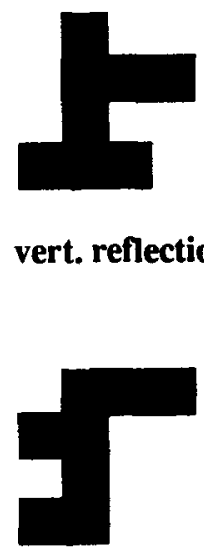

vert. reflection

n4

Figure 7. Unfamiliar stimuli for Experiments 5, 6, and 7. (A) Two series (a1 and a2) with a target and five distractors each, differing from the target by 1,2,3,4, and 6 elements, used in Experiment 5 . (B) Series b1: The target and distractors with various simple relationships to the target, used in Experiment 6, Part 1. Series b2: The target and five unrelated distractors, one old (unrelated 1 in b1) and four new (n1 to n4), used in Experiment 6, Part 2. 
formations of familiar stimuli. This familiarity might have affected the perceived similarity of the stimuli and thus interacted with the effects of physical difference and the more global influence of the transformations. In the next three experiments, unfamiliar stimuli were used to study the effects of physical difference (Experiment 5) and the same simple transformations (Experiment 6). The similarity of these stimuli was scaled directly in Experiment 7.

\section{Method}

Subjects. Two of the authors (M.v.G., S.D.) and 4 naive undergraduate students served as subjects.

Stimuli. The stimuli were constructed by using a square matrix of $4 \times 4$ little squares, eight of which were filled with black, the rest remaining white just as the background. Two constraints were applied: the little black square elements were to constitute one continuous form, and this form was to span the whole extent of the matrix. The size of the matrix was $2.2^{\circ} \times 2.2^{\circ}$. Other parameters were as in Experiment 1. Two different target stimuli were chosen, and 5 distractors were constructed for each of them. The distractors had physical differences of $1,2,3,4$, and 6 , with physical difference defined as the number of black squares that had to be moved from one place in the matrix to another in order to change the target into the respective distractor. These stimuli are shown in Figure 7A. They were again presented on the color monitor of a Macintosh II computer.

Procedure. The procedure was the same as that described in Experiment 1 . The 10 conditions (five levels of physical difference for two targets) were presented in a different random order for each observer, usually divided into two equally long sessions. The display sizes were 2,8 , and 16 items.

\section{Results and Discussion}

Error rates were generally below $10 \%$ without evidence for speed-accuracy tradeoffs (see Table 4). In Figures 8A$8 \mathrm{C}, \mathrm{RT}$ is graphed as a function of display size for three examples of physical difference $(1,3$, and 6). Mean RT decreased very drastically with increasing physical difference $[F(4,20)=59.7, p<.0001]$. For all levels of physical difference, RT for target absent was significantly longer than RT for target present $[F(1,5)=47.0, p<.001]$. The significant interaction between physical difference and display size $[F(8,40)=44.6, p<.0001]$ indicates that processing difficulty decreased with increasing physical difference. The slopes of the RT-display size relationship
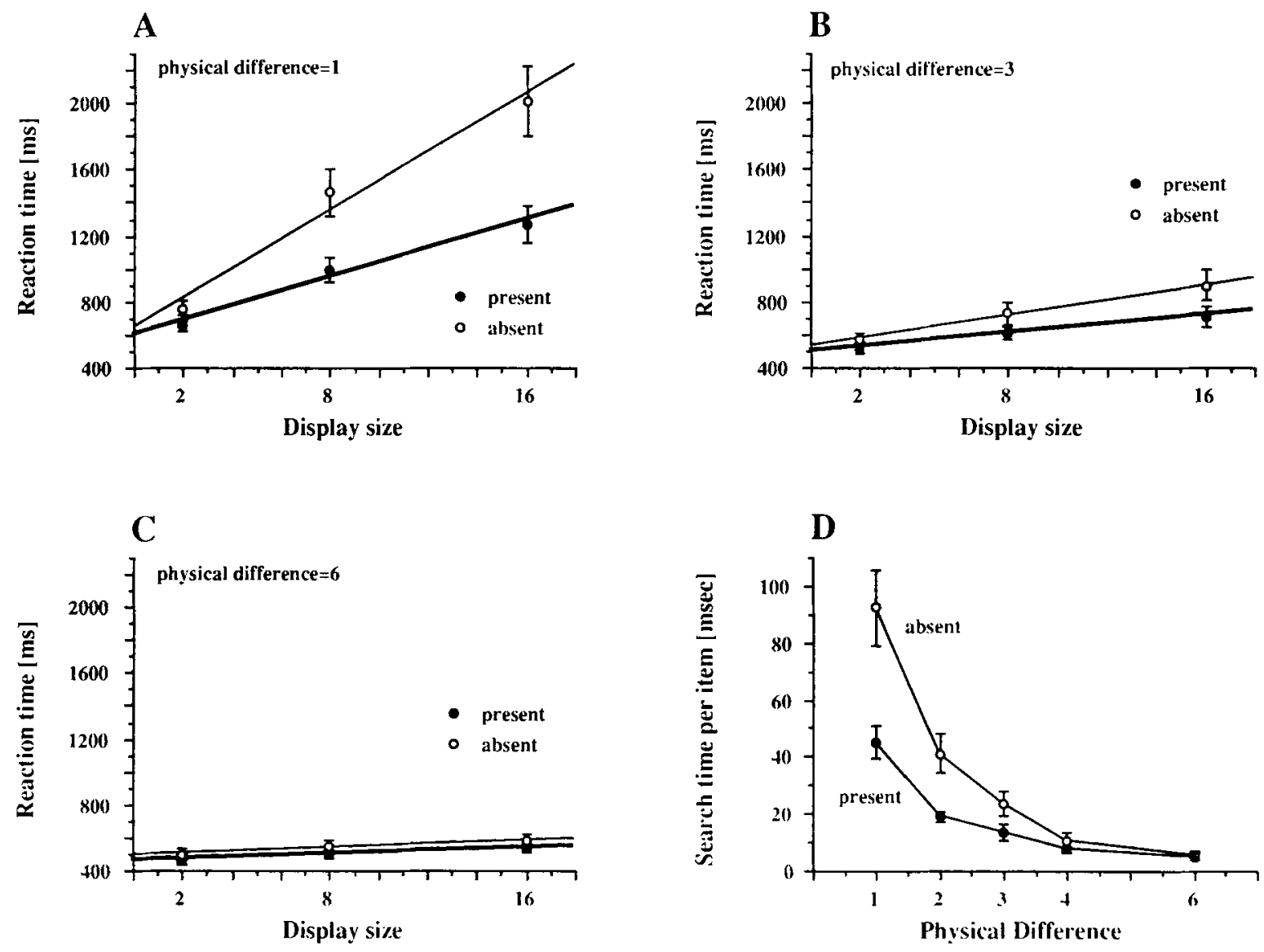

Figure 8. (A-C) Reaction times as a function of display size for three levels of physical difference as the average of 6 observers with standard errors. Target present and absent trials with their linear regression functions are graphed for the stimuli in Figure 7A, which were used in Experiment 5. (D) Mean processing times (slopes) as a function of physical difference between target and distractors for target present and absent trials with standard errors. 
were calculated as before and are plotted as search time per item as a function of the physical difference between target and distractor in Figure 8D. The parameter is target present/absent. The results were essentially the same for the two groups of stimuli, and they were therefore combined in this graph and the statistics.

As the physical difference increases, search time per item decreases smoothly for target present and absent $[F(4,20)$ $=47.7, p<.0001]$, the latter giving consistently longer search times $[F(1,5)=70.6, p=.0004]$, and, except for the largest physical difference, they stand in a 1:2 relationship. Thus, a serial, self-terminating model might apply in these cases. With a physical difference of 6 , the target is detected very quickly and the slopes are essentially identical, which could be considered as parallel processing. This relationship is similar to the one that was found for familiar stimuli in Experiments 1 and 2 with respect to the monotonic decrease, and it stresses again that physical difference is a strong (though not the only) determinant of processing time in a visual search task. This variable and others might be conceived of as operating through their effect on the perceived similarity between target and distractor. The present results for unfamiliar stimuli are much clearer than those for familiar stimuli, perhaps due to the lack of interference of stimulus familiarity.

\section{EXPERIMENT 6}

In this experiment, we attempted to keep the influence of physical difference constant and examined the effects of the same simple transformations between target and distractor that were used in Experiments 3 and 4. Here this was done for our unfamiliar stimuli. In Part 1, a target stimulus was paired with two unrelated distractors and three distractors that were transformations of the target. Since the two unrelated distractors gave very different results, some more unrelated distractors were used in Part 2, which was run in separate sessions.

\section{Method}

Subjects. Two of the authors (M.v.G., S.D.) and 4 naive undergraduate students served as the observers.

Stimuli. The stimuli were similar to or the same as those used in Experiment 5. They are shown in Figure 7B, Series b1 for Part 1 and Series b2 for Part 2. The target stimulus always had a constant physical difference of 4 with respect to all distractors. In Part 1 , the distractors were either two unrelated stimuli, or the target stimulus with rotation, horizontal reflection, or vertical reflection. In Part 2, the distractors were one of the unrelated stimuli used in Part 1, and four new unrelated stimuli.

Procedure. The same procedure was followed as before. The five conditions for each part were all presented in one session each, in a different random order to each observer. The display sizes were 2,8 , and 16 items.

\section{Results and Discussion}

Part 1. As before, error rates were generally below $10 \%$ without evidence for speed-accuracy tradeoffs (see Table 4). In Figures 9A-9D, RT is graphed as a func-
A

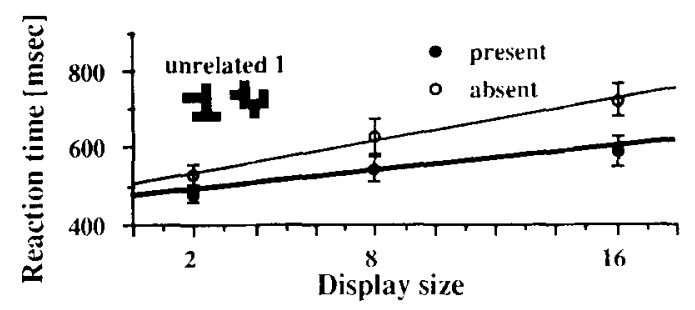

B

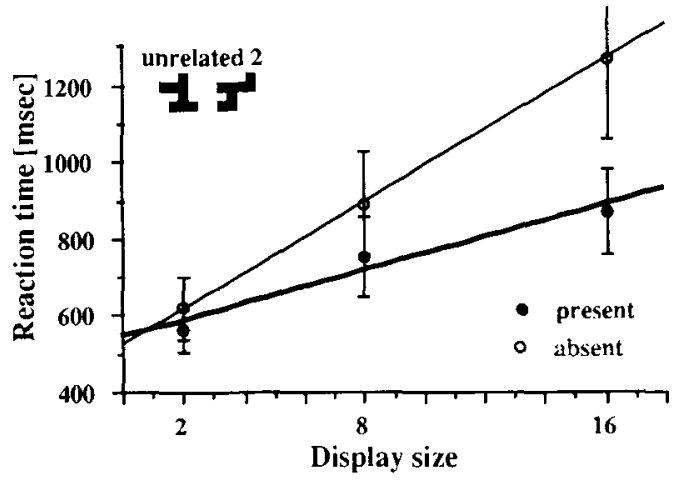

C

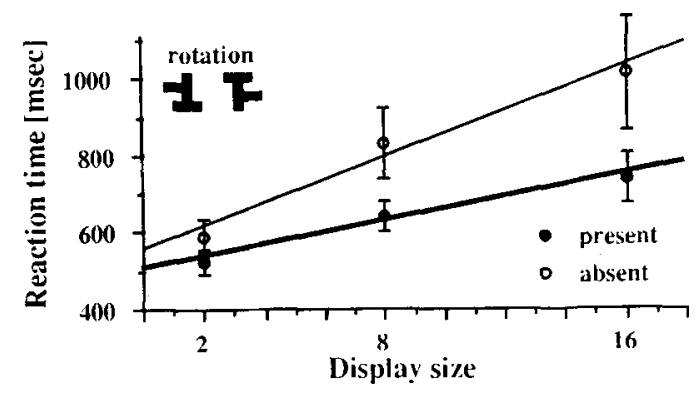

Figure 9. (A-D: above and facing page, top left) Reaction times as a function of display size for four different distractors (two unrelated, one rotation, one vertical reflection) as the average of $6 \mathrm{ob}-$ servers, with standard errors. Target present and absent trials with their linear regression functions are graphed for the stimuli in Figure 7B, Series b1, which were used in Experiment 6, Part 1. 
D

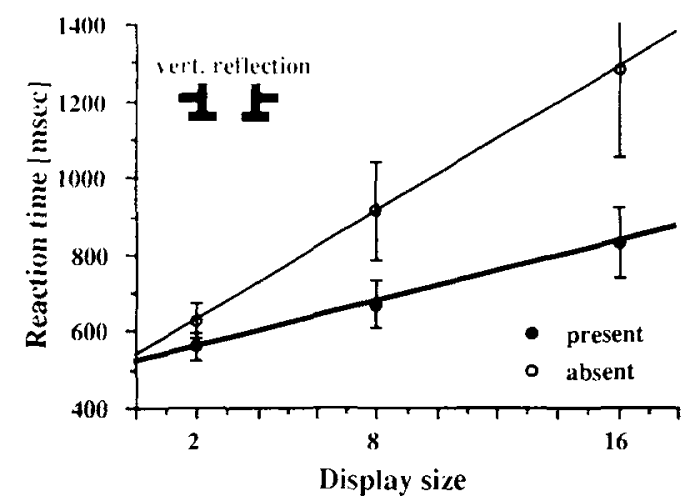

$\mathbf{E}$

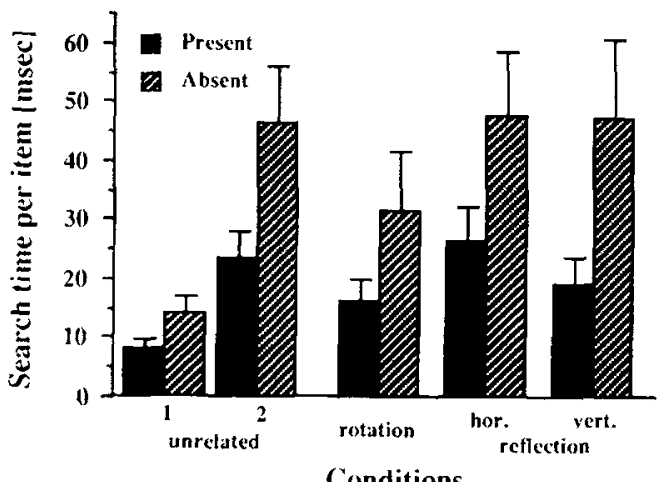

Conditions

F

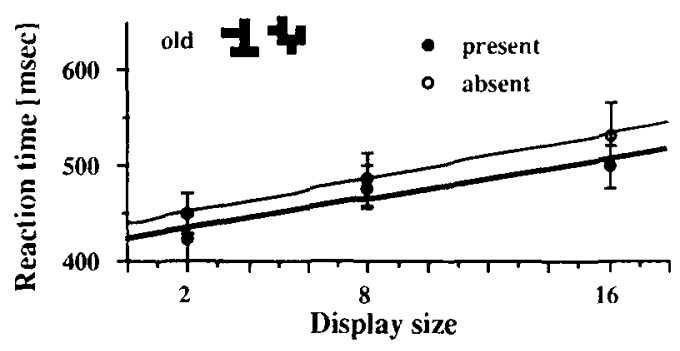

G

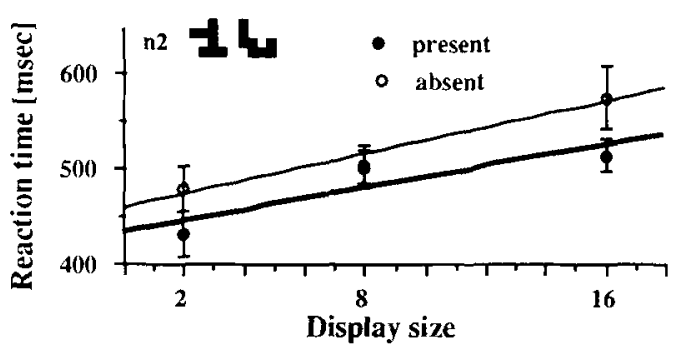

H

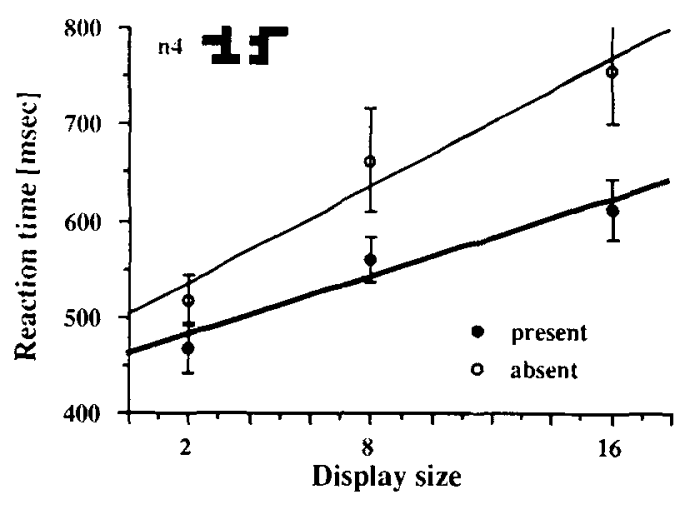

I

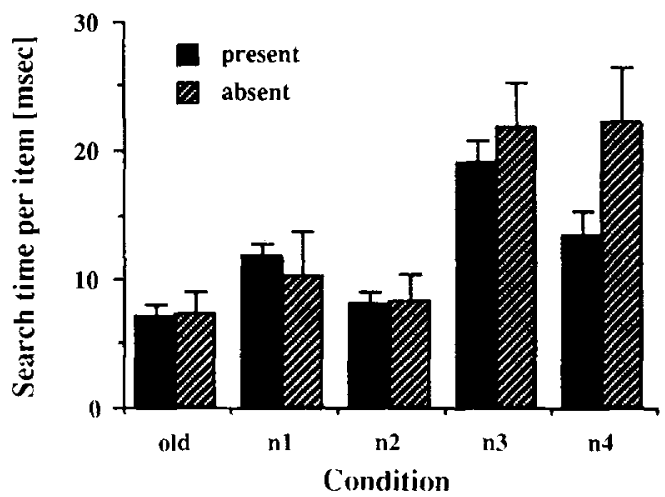

Figure 9, continued. (E) Search times per item (slopes) for target present and absent trials for all stimulus pairs with various simple transformations between target and distractor. Means with standard errors. (F-H) Reaction times as a function of display size for three different unrelated distractors (one old and two new) as the average of 6 observers, with standard errors. Target present and absent trials with their linear regression functions are graphed for the stimuli in Figure 7B, Series b2, which were used in Experiment 6, Part 2. (I) Search times per item (slopes) for target present and absent trials for all unrelated target-distractor pairs. Means with standard errors. 
tion of display size for the two unrelated distractors and for rotation and vertical reflection. Search times per item were determined as before and are graphed for all distractors in Figure 9E. One of the unrelated distractor stimuli was processed as quickly as can be expected from Experiment 5 , for a physical difference of 4 . The other one, however, also with a physical difference of 4 , was processed much more slowly (see General Discussion and Part 2). In view of this, we compared the results separately for the two unrelated stimuli. When the first one was used, the search times for it and the three transformations differed significantly $[F(3,15)=6.4, p=.0054]$, with the unrelated stimulus being different from the $\mathrm{hr}$ and vr transformations $(p<.01$ on $t$ test or Duncan post hoc test). When the second unrelated stimulus was used, there were no significant differences $[F(3,15)=1.85$, $p=.181]$. In both cases, target present/absent was significant $[F(1,15)=13.5, p=.014$ and $F(1,15)=14.2$, $p=.013$, respectively]. The fact that absent trials had slopes that were about twice those for the present trials may suggest serial processing. These results are similar to those for familiar stimuli for the first unrelated stimulus only: when target and distractor are related by a simple transformation, especially a horizontal or vertical reflection, they appear more similar and search times are increased.

Part 2. Error rates were as in Part 1 (see Table 4). In Figures $9 \mathrm{~F}-9 \mathrm{H}, \mathrm{RT}$ is graphed as a function of display size for the old unrelated distractor (unrelated 1) and two of the new ones. One of those (new2) behaved similarly as the unrelated 1 distractor in Part 1 (= old in Part 2), whereas the other (new4) was more like unrelated 2 in Part 1. Search times per item are shown for all distractors in Figure 9I. An ANOVA showed that the five distractors were significantly different from each other $[F(4,20)=14.6, p<.00001]$. Post hoc analyses $[p<$ .05 on Tukey (HSD) test] showed that Distractors new3 and new4 differed from the others (old, new1, new2), which were not significantly different from each other. These results show that some unrelated stimuli appear to be quite similar to the target stimulus and thus cause steep slopes, even though they have the same physical difference of 4 , just as others appear much less similar and are easy to discriminate. The present results raise two further questions for future research: (1) Does familiarity interact with the effects of transformations on similarity? (2) What accounts for the differences between the various unrelated stimuli? All had the same physical differ- ence with respect to the target and all were unrelated to the target. Some other global characteristic (like "blobbiness") may be involved, perhaps exemplified by the number of corners or edges.

\section{EXPERIMENT 7}

As in Experiment 4, we wanted to establish the degree of similarity for the stimulus pairs of Part 1 of Experiment 6 and for Experiment 5 also in a direct way. This was necessary, in order to avoid circular argumentation in the implication of similarity between target and distractors in visual search tasks. We therefore used the same scaling approach, also with the unfamiliar stimuli.

\section{Method}

Subjects. There were 62 subjects ( 56 fernale, 6 male) from undergraduate psychology classes at the University of Sao Paulo in Ribeirao Preto, Brazil, in the experiment.

Stimuli. Each target-distractor pair that was utilized in Experiments 5 and 6, Part 1 (see Figure 7) was reproduced in black and placed with the target and distractor side by side on a white card $(7.2 \times 3.0 \mathrm{~cm})$. Each stimulus occupied an area of $2.1 \times 2.1 \mathrm{~cm}$, separated from its partner by $2.0 \mathrm{~cm}$. On each card, the target was to the left of the distractor. In the center of each card, an arrow indicated the orientation in which the pair was to be judged. A number and a letter on the back of each card identified each stimulus pair.

Procedure. Each subject received three envelopes, each containing one of the three series of five cards with the target-distractor pairs. The subjects were instructed to open the envelopes at random, to observe the five stimulus pairs and to order them into a column where the first rank was occupied by the most similar pair, the last one by the least similar pair, and the intermediate positions by pairs of intermediate similarity. This was done separately for the contents of each envelope. In this way, we obtained for each of the three series of target-distractor pairs five categories of similarity.

\section{Results and Discussion}

In this experiment, the similarity of the target-distractor pairs was estimated by the mean ranking of each stimulus pair. The estimates of similarity for the three series are shown in Table 3.

Each subject's estimates for the three series of stimuli were submitted to a Friedman ANOVA, which indicated that for each series the differences between the five categories of similarity were significant, all with $p<.0001$ and $d f=4$ : for Series a 1 of Experiment $5, \chi^{2}=110.5$; for Series a 2 of Experiment $5, \chi^{2}=227.3$; and for Experiment 6 , Part $1, \chi^{2}=142.3$.

The rankings of adjacent pairs in each series were then compared in a Wilcoxon signed-rank test. In Series al

Table 3

Mean Rank for All Target-Distractor Pairs Used in Experiment 7

\begin{tabular}{|c|c|c|c|c|}
\hline \multirow{2}{*}{$\begin{array}{c}\text { Distractor From } \\
\text { Experiment } 5\end{array}$} & \multicolumn{2}{|c|}{ Mean Rank } & \multirow{2}{*}{$\begin{array}{c}\text { Stimulus Pair } \\
\text { From Experiment 6, } \\
\text { Part } 1\end{array}$} & \multirow[b]{2}{*}{ Mean Rank } \\
\hline & Series al & Series a2 & & \\
\hline $\mathrm{d} 1$ & 1.41 & 1.21 & unrelated 1 & 4.63 \\
\hline d2 & 2.28 & 1.98 & unrelated2 & 3.59 \\
\hline d3 & 3.49 & 2.71 & rot & 2.63 \\
\hline $\mathrm{d} 4$ & 3.56 & 3.95 & hr & 2.29 \\
\hline d6 & 3.92 & 4.90 & vr & 1.62 \\
\hline
\end{tabular}


of Experiment 5, the distractor $\mathrm{d} 3$ could not be considered to be more similar to the target than the distractor $\mathrm{d} 4$, and the similarity between $\mathrm{d} 4$ and the target could not be considered as greater than that between $\mathrm{d} 6$ and the target. In the series of Experiment 6, only the pairs rot and $\mathrm{hr}$ could not be seen as having different levels of similarity. All the other pairs were significantly different from each other $(p<.001)$.

The perceived similarities between targets and distractors in Figure 7A are directly related to the physical differences between them. The correlation between the two means was equal to or exceeded 0.90 in both cases $(0.90$ for a 1 and 0.99 for a2). The relationship of similarity between the stimuli of Experiment 6, Part 1 was practically the same as that obtained in Experiment 4: the most similar stimuli were those of the transformation vr, followed by hr and rot. Also as in Experiment 4, the nonrelated stimuli were the least similar. It is curious, however, that the two unrelated distractors had similar ratings of similarity to the target but produced quite different RT functions.

The difference between the effects of similarity in visual search tasks and judgment tasks could be that in visual

Table 4

Mean Error Scores for Visual Search Experiments

\begin{tabular}{|c|c|c|c|c|c|c|c|c|}
\hline \multicolumn{9}{|c|}{ Display Size } \\
\hline & \multicolumn{5}{|c|}{ Experiment 1} & \multicolumn{3}{|c|}{ Experiment 2} \\
\hline & $\begin{array}{c}\text { Physical } \\
\text { Difference 1 }\end{array}$ & $\begin{array}{c}\text { Physical } \\
\text { Difference 2 }\end{array}$ & $\begin{array}{rr} & \text { Phy } \\
2 & \text { Differ }\end{array}$ & ical & $\begin{array}{l}\text { Physical } \\
\text { Difference } 4\end{array}$ & & $\begin{array}{l}\text { Physical } \\
\text { Difference } 1\end{array}$ & $\begin{array}{c}\text { Physical } \\
\text { Difference } 3\end{array}$ \\
\hline 1 & 2.42 & 1.25 & 4 & & 0.75 & & 1.03 & 2.28 \\
\hline 6 & 4.42 & 4.83 & 5 & & 3.25 & & 2.94 & 3.77 \\
\hline 12 & 9.92 & 5.17 & 6. & & 6.50 & & 2.80 & 3.56 \\
\hline 1 & 3.00 & 1.67 & 4. & & 4.00 & & 1.52 & 2.44 \\
\hline 6 & 2.42 & 1.92 & 1. & & 3.25 & & 2.37 & 3.17 \\
\hline \multirow[t]{3}{*}{12} & 2.92 & 1.00 & 2 & & 0.75 & & 3.05 & 2.65 \\
\hline & \multicolumn{5}{|c|}{ Experiment 3} & & & \\
\hline & Unrelated & $\begin{array}{l}\text { Horizontal } \\
\text { Reflection }\end{array}$ & & ation & $\begin{array}{l}\text { Vertical } \\
\text { Reflection }\end{array}$ & & & \\
\hline 2 & 1.25 & 1.00 & & .50 & 2.67 & & & \\
\hline 8 & 8.25 & 7.17 & & .50 & 5.50 & & & \\
\hline 16 & 15.58 & 22.33 & & .50 & 15.17 & & & \\
\hline 2 & 1.58 & 9.17 & & .17 & 5.00 & & & \\
\hline 8 & 2.50 & 1.00 & & .67 & 1.67 & & & \\
\hline \multirow[t]{3}{*}{16} & 1.33 & 4.83 & & .17 & 3.33 & & & \\
\hline & \multicolumn{7}{|c|}{ Experiment 5} & \\
\hline & $\begin{array}{c}\text { Physical } \\
\text { Distance } 1\end{array}$ & $\begin{array}{c}\text { Physical } \\
\text { Distance 2 }\end{array}$ & $\begin{array}{l}\text { Phy } \\
\text { Diste }\end{array}$ & $\begin{array}{l}\text { sical } \\
\text { nce } 3\end{array}$ & $\begin{array}{l}\text { Physical } \\
\text { Distance } 4\end{array}$ & & $\begin{array}{l}\text { Physical } \\
\text { istance } 6\end{array}$ & \\
\hline 2 & 2.08 & 2.67 & & 92 & $\overline{1.92}$ & & 2.42 & \\
\hline 8 & 10.83 & 7.25 & & 42 & 4.42 & & 2.25 & \\
\hline 16 & 25.58 & 14.58 & & 75 & 6.67 & & 7.50 & \\
\hline 2 & 3.33 & 2.75 & & 92 & 1.00 & & 1.75 & \\
\hline 8 & 2.08 & 1.00 & & 33 & 1.08 & & 2.25 & \\
\hline \multirow[t]{3}{*}{16} & 3.00 & 1.58 & & 58 & 1.83 & & 1.58 & \\
\hline & \multicolumn{7}{|c|}{ Experiment 6} & \\
\hline & Unrelated & $\begin{array}{l}\text { Horizontal } \\
\text { Reflection }\end{array}$ & Rotation & $\begin{array}{c}\text { Vertical } \\
\text { Reflection }\end{array}$ & Old & $\mathrm{n} 2$ & n4 & \\
\hline 2 & 3.53 & 1.95 & 3.63 & 2.67 & 2.67 & 0.50 & 2.83 & \\
\hline 8 & 4.76 & 4.21 & 3.88 & 5.51 & 3.83 & 4.83 & 6.50 & \\
\hline 16 & 5.34 & 4.67 & 4.54 & 7.83 & 1.50 & 4.83 & 11.67 & \\
\hline 2 & 2.58 & 1.79 & 2.83 & 3.55 & 1.00 & 1.00 & 2.50 & \\
\hline 8 & 2.94 & 2.73 & 2.67 & 2.80 & 0.00 & 0.00 & 3.67 & \\
\hline 16 & 5.28 & 3.84 & 4.79 & 4.07 & 0.50 & 2.00 & 2.67 & \\
\hline
\end{tabular}


search the stimuli are treated as texture, whereas in a judgment task the pairs are treated as individual objects and compared two by two (Beck, 1966; Treisman \& Gormican, 1988). In a visual search task, the detection of a texture change would be sufficient for the subject to infer the presence of the target without the need of a comparison process, which is necessary in a judgment task. In this case, the processes involved in the two tasks must be different, and consequently the correlation between their parameters would be low, as was the case in the study by Beck (1966). In our case, on the other hand, in both Experiments 4 and 7, the correlation between the rankings and the slopes of the RT-display size functions give support to the contention that very similar mechanisms are involved in the two tasks.

\section{GENERAL DISCUSSION}

Our aim in this study was to examine some variables that determine the ease with which a target can be found among a group of distractors in a visual search task. The physical difference between two stimuli, without the use of any particular structure, was found to have a very precise, yet general, effect on search time: the greater the difference, the faster the search. This was true for familiar and unfamiliar stimuli alike. The smooth monotonic relationship between search time per item (processing time) and physical difference could furthermore be shifted to higher or lower processing time values by simply decreasing or increasing the overall size of the stimuli.

These results seem to speak against the strict dichotomy of parallel and serial processes as underlying preattentive and attentive visual analyses, respectively, that has been suggested previously (Treisman, 1986; Julesz, 1984, 1986). Throughout this paper, reference has been made to this dichotomy, but many problems and inconsistencies have been encountered and pointed out. For example, in Experiments 1 and 2 , the fact that the slopes for target present and absent are very similar can be considered as evidence for parallel processing (Humphreys et al., 1989) or serial exhaustive processing. On the other hand, the slope is affected by the physical difference throughout the tested range, which could be considered as evidence for serial self-terminating processing. In Experiment 5, however, processing time for target absent was about twice that for target present until they became equal at high values of physical difference. Again, there was no evidence for an abrupt change from serial to parallel. Rather, a continuous change from long processing times to very short processing times without categorical boundary might be a better way to account for these observations (Duncan \& Humphreys, 1989). Furthermore, it may be that it is not possible to infer the type of processing simply by using the slopes (Egeth \& Dagenbach, 1991). Other indices will have to be taken into consideration.

As we have mentioned, our choice of the definition of physical difference was arbitrary, and we do not know whether it constitutes an appropriate measure of physical similarity. This is particularly crucial for letters and digits, where a change of physical difference was often also accompanied by the removal or addition of elements, not just a rearrangement of a given number of elements. Although this is unavoidable for this kind of stimulus set, it might have introduced special effects for particular stimuli. The variability observed within a level of physical difference might be partially the result of this. The situation is somewhat better for the set of nonsense stimuli, where the number of elements was kept constant. Yet, our experiments show that physical difference can generally account for similarity only in a rudimentary way.

Physical difference was not the only variable that affected the speed of visual search. When the target and distractor were not unrelated but were related by a transformation such as a $180^{\circ}$ rotation or a reflection on the horizontal or vertical axis, processing times were increased. It is plausible that items that are related by these transformations are perceived to have greater similarity than items that differ by the same amount of physical difference but are not related by transformations. This hypothesis was supported for familiar stimuli by direct scaling of stimulus similarity. Though not perfect, the correlation between the slopes of the visual search experiment and the ratings of similarity judgments is strong enough to suggest that stimulus similarity is an important factor of visual search performance. This does not exclude the possibility that other stimulus properties may influence search times independently of similarity. It furthermore follows from our results that familiarity is another important variable that may determine the effectiveness of transformational relatedness on perceived similarity. This conclusion is based on the results of Experiments 3 and 6, in which transformational relatedness had a clear effect for the familiar letters and numbers but was only marginally evident for the unfamiliar nonsense stimuli. The more general effect of familiarity on similarity will be investigated in future experiments. In general, then, both physical difference and relatedness by transformations may be seen as contributing to the degree of similarity between target and distractor. And the more similar the two stimuli are perceived to be, the more time it will take for each comparison. This kind of similarity effect has been reported previously in various forms (see, e.g., Neisser, 1967; Nickerson, 1967; Pashler 1987; Taylor, 1976).

One could furthermore imagine that other factors may contribute to similarity, such as symmetry or global shape (e.g., "blobbiness," elongatedness, free terminators, number of corners or edges, oriented low spatial frequency bands, etc.). It has already been shown that symmetry can influence similarity in more than one way (Wolfe \& Friedman-Hill, 1992). When any of these factors results in high perceived similarity, processing times can be expected to be long. It is not known whether low levels of these factors will give very short processing times (akin to parallel processing), except in the case of physical similarity, where this is possible. It is also unknown how these factors may interact. The difference between 
the two unrelated stimuli in Experiment 6, Part 1, might have been due to such factors (the first one may be more blobby and have more corners or edges than the second one). These factors will have to be investigated in future research.

It is tempting to suppose that in a visual search task the subject compares each stimulus with a target template, as Duncan and Humphreys (1989) proposed. The time needed for this comparison is directly proportional to the similarity that exists between the stimulus to be compared and the target template. On the other hand, to consider the effect of similarity only on the comparison time does not take account of those cases in which the similarity is very small. In those cases, it is difficult to accept that any stimulus in the visual field could be coded (or could have access to short-term memory, according to Duncan \& Humphreys, 1989) and compared in less than $10 \mathrm{msec}$. This was the case, for example, when the physical difference was greater than 4 in Experiment 5 . In this situation, the strategy must be different. Perhaps a decision could be made on the basis of information that does not depend on a process of comparison, as seems to be the case in parallel processing.

What is the relationship of this similarity analysis to the preattentive and attentive processing dichotomy? It seems that models in which the change of the involvement of attentional resources is viewed as a continuous (or multistep) rather than a dichotomous process would give a better account of the present results. Alternatively, one could retain the two basic processes of parallel and serial search, but allow for a differential involvement of the two, depending on the amount of similarity between target and distractors. If they are very dissimilar, only the parallel process would be needed to detect the target. As similarity increases, more and more involvement of the serial process would be required to reject distractors. Finally, with high similarity, only the serial process could be used to find the target.

Although our results certainly emphasize the importance of target-distractor similarity in determining search times, they do not speak to the case in which stimuli are defined by a conjunction of two different dimensions. Some recent data (Treisman, 1991) suggest that conjunctions might affect search times in a special way in addition to simple stimulus differences. It remains to be shown, however, whether this effect may not also work through perceived similarity.

\section{REFERENCES}

BECK, J. (1966). Effect of orientation and of shape similarity on perceptual grouping. Perception \& Psychophysics, 1, 300-302.

BECK, J. (1982). Textural segmentation. In J. Beck (Ed.), Organization and representation in perception (pp. 285-317). Hillsdale, $\mathrm{NJ}$ : Erlbaum.

DEHAENE, S. (1989). Discriminability and dimensionality effects in visual search for featural conjunctions: A functional pop-out. Perception \& Psychophysics, 46, 72-80.
Duncan, J., \& Humphreys, G. W. (1989). Visual search and stimulus similarity. Psychological Review, 96, 433-458.

Egeth, H., \& Dagenbach, D. (1991). Parallel versus serial processing in visual search: Further evidence from subadditive effects of visual quality. Journal of Experimental Psychology: Human Perception \& Performance, 17, 551-560.

Enns, J. T., Ochs, E. P., \& Rensink, R. A. (1990). VSearch: Macintosh software for experiments in visual search. Behavior Research Methods, Instruments, \& Computers, 22, 118-122.

EsTEs, W. K. (1972). Interactions of signal and background variables in visual processing. Perception \& Psychophysics, 12, 278-286.

FARMER, E. W., \& TAYLOR, R. M. (1980). Visual search through color displays: Effects of target-background similarity and background uniformity. Perception \& Psychophysics, 27, 267-272.

Guilford, J. P. (1954). Psychometric methods. New York: McGrawHill.

Hoffman, J. E. (1979). A two-stage model of visual search. Perception \& Psychophysics, 25, 319-327.

Humphreys, G. W., Quinlan, P. T., \& RidDOCh, M. J. (1989). Grouping processes in visual search: Effects with single- and combinedfeature targets. Journal of Experimental Psychology: General, 118, 258-279.

Johnson, S. C. (1967). Hierarchical clustering schemes. Psychometrica, 32, 241-254.

JuLESz, B. (1984). A brief outline of the texton theory. Trends in Neuroscience, 7, 41-45.

Julesz, B. (1986). Texton gradients: The texton theory revisited. Biological Cybernetics, 54, 245-261.

McInTyre, C., Fox, R., \& NeALE, J. (1970). Effects of noise similarity and redundancy on the information processed from brief visual displays. Perception \& Psychophysics, 7, 328-332.

NeIsser, U. (1967). Cognitive psychology. New York: AppletonCentury-Crofts.

NiCKERSON, R. S. (1967). Categorization time with categories defined by disjunction and conjunction of stimulus attributes. Journal of $E x$ perimental Psychology, 73, 211-219.

NothDURFT, H.-C. (1985). Sensitivity for structure gradient in texture discrimination tasks. Vision Research, 25, 1957-1968.

NothDURFT, H.-C. (1990). Texture segmentation is based on local dissimilarities. Investigative Ophthalmology \& Visual Science, 31 (Suppl.), 561.

NothDURFT, H.-C. (1991). The role of local contrast in pop-out of orientation, motion and color. Investigative Ophthalmology \& Visual Science, 32 (Suppl.), 714.

PASHLER, H. (1987). Target-distractor discriminability in visual search. Perception \& Psychophysics, 41, 285-292.

Podgorny, P., \& Garner,W. R. (1979). Reaction time as a measure of inter- and intraobject visual similarity: Letters of the alphabet. Perception \& Psychophysics, 26, 37-52.

Pomerantz, J. R., Sager, L. C., \& Stoever, R. G. (1977). Perception of wholes and their component parts: Some configurational superiority effects. Journal of Experimental Psychology: Human Perception \& Performance, 3, 422-435.

Prinzmetal, W., \& Banks, W. P. (1977). Good continuation affects visual detection. Perception \& Psychophysics, 21, 389-395.

QUiNLAN, P. T., \& HUMPHREYS, G. W. (1987). Visual search for targets defined by combinations of color, shape, and size: An examination of the task constraints on feature and conjunction searches. Perception \& Psychophysics, 41, 455-472.

SINGER, M. H., \& LAPPIN, J. S. (1976). Similarity: Its definition and effect on the visual analysis of complex displays. Perception \& Psychophysics, 19, 405-411.

TAYLOR, D. A. (1976). Holistic and analytic processes in the comparison of letters. Perception \& Psychophysics, 20, 187-190.

Treisman, A. (1986, November). Features and objects in visual processing. Scientific American, pp. 114B-125.

Treisman, A. (1988). Features and objects: The 40th Bartlett Memorial Lecture. Quarterly Joumal of Experimental Psychology, 40A, 201-237. 
Treisman, A. (1991). Search, similarity, and integration of features between and within dimensions. Journal of Experimental Psychology: Human Perception \& Performance, 17, 652-676.

Treisman, A., \& Gormican, S. (1988). Feature analysis in early vision: Evidence from search asymmetries. Psychological Review, 95 , 15-48.

Treisman, A., \& Paterson, R. (1984). Emergent features, attention and object perception. Journal of Experimental Psychology: Human Perception \& Performance, 10, 12-31.

Treisman, A., \& SATo, S. (1990). Conjunction search revisited. Journal of Experimental Psychology: Human Perception \& Performance, 16, 459-478.

VAN NES, F. L., \& Bouma, H. (1980). On the legibility of segmented numerals. Human Factors, 22, 463-474.
Wolfe, J. M., Cave, K. R., \& Franzel, S. L. (1989). Guided search: An alternative to the feature integration model for visual search. Journal of Experimental Psychology: Human Perception \& Performance, $15,419-433$.

Wolfe, J. M., \& Friedman-Hill, S. R. (1992). On the role of symmetry in visual search. Psychological Science, 3, 194-198.

WoOdworTH, R. S. (1938). Experimental psychology. New York: Holt.

(Manuscript received December 20, 1991; revision accepted for publication October 11,1993 .) 